\title{
THE EFFECT OF CHEMICAL ADDITIVES ON THE SYNTHESIS OF ETHANOL
}

\author{
Technical Progress Report 5 \\ Grant No. DE-FG22-87PC79923 \\ September 16, 1988 - December 15, 1988
}

by

Steven S. C. Chuang

Department of Chemical Engineering

University of Airon

Akron, Ohio $443 \% 5$

Date of Subinission: February 4,1989

US/DOE Patent Clearance is not required prior to the publication of this document.

\section{DISCLAIMER}

This report was prepared as an account of work sponsored by an agency of the United States Government. Neither the United States Grvernment nor any agency thereot, nor any of their employees, makes any warranty, express or implied, or assumes any legal liability or responsibility for the accuracy, completeness, or usefulness of any information, apparatus, product, or process disclosed, or represents that its use would not infringe privately owned rights. Reference herein to any specific commercial product, process, or service by trade name, trademark, manufarturer, or otherwise does not necessarily constitute or imply its endorsement, recommendation, or favoring by the United States Government or any agency thereof. The views and opinions of authors expressed herein do not neccessarily state or reflect those of the United States Government or any agency thereof. 


\section{SUMMARY}

The objective of this research is to elucidate the role of various chemical additives on ethanol synthesis over fh- and $\mathrm{Ni}$-based catalysts. Chemical additives used for this study will include $S, P, A g, C u, M n$, and $N a$ which have different electronegativities. The effect of additives on the surface state of the catalysts, heat of adsorption of reactant molecules, reaction intermediates, reaction pathways, reaction kinetics, and product distributions is/will be investigated by a series of experimental studies including temperature programmed desorption, infrared study of No adsorption, reactive probing, steady state rate measurement, and transient kinetic study.

A better understanding of the role of additive on the synthesis reaction may allow us to use chemical additives to manipulate the catalytic properties of $\mathrm{Rh}$ - and $\mathrm{Ni}$-based catalysts for producing high yields of ethanol from syngas.

RESULTS TO DATE CO insertion is known to be a key step to the formation of acetaldehyde and ethanol from co hydrogenation over Rh catalysts. Ethylene hydroformylation has often served as a probe to determine co insertion capabilities of Rh catalysts. However, the mechanism of $\mathrm{CO}$ insertion in hydroformylation on the supported Rh is still not well understood. During the fifth quarter of the project, the mechanism of co insertion in ethylene hydroformylation over $\mathrm{Rh} / \mathrm{SiO}_{2}$ was investigated by insitu infrared spectroscopy. 


\section{Introduction}

Hydroformylation, which is a reaction of an olefin with syngas to form an aldehyde, is well known to be a homogeneous reaction catalyzed by metal complexes [1-3]. The reaction was first discovered by Roelen in 1938 while investigating the mechanism of the Fischer-Tropsch (F-T) synthesis by the addition of ethylene to syngas [4]. It was found that a significant amount of added ethylene was converted to propionaldehyde over a heterogeneous cobalt catalyst (a conventional $F-T$ catalyst) under the $F-T$ condition. The selectivity to propionaldehyde was significantly enhanced by increasing reaction pressures over $5.1 \mathrm{MN} / \mathrm{m}^{2}$ and decreasing temperatures below $423 \circ \mathrm{K}$ in which the $\mathrm{F}-\mathrm{T}$ reaction ceased to occur. The overall reaction proceeds according to

$$
\mathrm{CO}+\mathrm{H}_{2}+\mathrm{C}_{2} \mathrm{H}_{4}--->\mathrm{C}_{2} \mathrm{H}_{5} \mathrm{CHO}
$$

It was the conventional $F-T$ cobalt catalyst which was first used as a hydroformylation catalyst in a fixed bed reactor $[4,5]$. It was later recognized that the hydroformylation is a homogeneous reaction catalyzed by the cobalt carbonyls $[1,5-7]$. The conventional F-T cobalt catalyst (cobalt metal) was indeed a precursor for the generation of cobalt carbonyls for the reaction. The identification of hydroformylation as a homogeneously catalyzed reaction has essentially led to the successful development of commercial hydroformylation processes with Co and Rh complex catalysts [1-3].

While Roelen discuvered the hydroformylation by the addition 
of ethylene to syngas on the F-T catalyst, the approach using olefin addition as a probe reaction has been extensively employed to study reaction intermediates and secondary reactions in the F-T synthesis as well as $C O$ insertion capability of the F-T catalysts [8-15]. The addition of ethylene into syngas was found to increase the rate of formation of propionaldehyde over supported $R h$ and $R u$ under the $F-T$ condition in which the $F-T$ reaction continues to proceed [8-10]; the addition of 1-butene led to an increase in the rate of formation of 1-pentanol over $\mathrm{Fe} / \mathrm{Al}_{2} \mathrm{C}_{3}$ under the similar reaction condition [11]. Interestingly, homogeneous counterparts of both supported Rh and $R u$ (i.e., Rh and Ru complexes) are well known to catalyze homogeneous hydroformylation while Fe complexes are known to be active for hydroformylation with $\mathrm{CO} / \mathrm{H}_{2} \mathrm{O}[1-3]$. The homogeneous hydroformylation on metal complexes generally takes place under high co pressures and low temperatures in which the metal complex catalyst is stable; the reaction is highly selective with hydrogenation products as minor products.

The results of olefin addition to syngas is strikingly similar to those observed for Co catalysts by Roelen. The interesting similarity in the reaction of olefins with syngas to form aldehydes on both supported metals and metal complexes has led to the investigation of the relationships between the (heterogeneous) hydroformylation and the homogeneous hydroformylation. It is important to point out here that the 
hydroformylation is well accepted as homogeneous reaction catalyzed by metal complexes. In this paper, we tentatively use the term, heterogeneous hydroformylation, to describe the reaction of olefins with syngas to form aldehydes over supported metal catalysts.

The mechanism of homogeneous hydroformylation has been well established whereas little is known about the mechanism of heterogeneous hydroformylation. To develop a better understanding of heterogeneous hydroformylation, co adsorption, co hydrogenation (the F-T reaction), and ethylene hydroformylation on $R h / S_{i C 2}$ were studied by in situ infrared spectroscopy (JR). Rh was used for this study because of its high activity for both homogeneous and heterogeneous hydroformylation and existence of voluminous literature data on homogeneous hydroformylation on $\mathrm{Rh}$ complexes for comparison with heterogeneous hydroformylation [17]. $\mathrm{H}_{2} \mathrm{~S}$ was used as a selective poison to probe the nature of the reaction since sulfur compounds can severely poison the $F-T$ reaction but only inhibit the homogeneous hydroformylation to a limited extent $[16,17]$. The results were compared with those for homogeneous hydroformylation to elucidate the relationships between heterogeneous and homogeneous hydroformylation.

\section{Experimental}

\section{Catalyst Preparation}

Three wt. \% $\mathrm{Rh} / \mathrm{SiO}_{2}$ was prepared by impregnation of $\mathrm{SiO}_{2}$ (Strem Chemicals) using Rh chloride (Alfa Chemicals). After 
impregnation, the sample was dried overnight in air at $313^{\circ} \mathrm{K}$, then reduced in flowing hydrogen at $673^{\circ} \mathrm{K}$ for $16 \mathrm{hr}$. Hydrogen flow chenisorption was used to determine the metal surface area of $\mathrm{Rh} / \mathrm{SiO}_{2}$ and sulfur coverage on the sulfided $\mathrm{Rh} / \mathrm{SiO}_{2}$. The crystalline size of the Rh metal was determined to be $130^{\circ} \mathrm{A}$ by $X$-ray line broadening technique.

Reaction Studies

Both co hydrogenation and ethylene hydroformylation were performed over $\mathrm{Rh} / \mathrm{SiO} 2$ before and after sulfidation with $\mathrm{H}_{2} \mathrm{~S}$ in $a$ differential reactor system under $393-573 \circ \mathrm{K}$ and $1.01 \mathrm{MN} / \mathrm{m}^{2}$. Product distribution was determined by using an HP-5890A gas chromatograph.

\section{Sulfidation}

$\mathrm{H}_{2} \mathrm{~S}\left(1000 \mathrm{ppm}\right.$ of $\mathrm{H}_{2} \mathrm{~S}$ in $\left.\mathrm{H}_{2}\right)$ was passed at $15 \mathrm{cc} / \mathrm{min}$. through the catalyst at 573 or $673 \circ \mathrm{K}$ for about 30 minutes in order to saturate the catalyst surface with sulfur. Hydrogen was then passed through the catalyst bed for about 1 hour at the same temperature to remove any weakly adsorbed sulfur. Hyỏrogen chemisorption and temperature programmed desorption study shown that the catalyst was incapable of chemisorbing $H_{2}$ after sulfidation indicating that the metal surface may be saturated with adsorbed sulfur [17]. It was found that sulfidation with either pure $\mathrm{H}_{2} \mathrm{~S}$ or $1000 \mathrm{ppm} \mathrm{H_{2 } S}$ in $\mathrm{H}_{2}$ led to the sulfided catalysts which exhibit the same hydroformylation activities. 


\section{In Situ Infrared Spectroscopic (IR) Studies}

Adsorption of $\mathrm{CO}$, co hydrogenation, and ethylene hydroformylation on $\mathrm{Rh} / \mathrm{SiO}_{2}$ and sulfided $\mathrm{Rh} / \mathrm{SiO}_{2}$ were studied in an $\mathrm{IR}$ cell at $5100^{\circ} \mathrm{K}$ and $1.01 \mathrm{MN} / \mathrm{m}^{2}$. The IR cell is made of stainless steel with CaFr window using Grafoil o-rings (Union Carbide). The catalysts for the study were grounded to a fine powder and pressed into a disk $10 \mathrm{~mm}$ in diameter and $2 \mathrm{~mm}$ in thickness with $25 \mathrm{mg})$. IR spectra of adsorbed species were recorded by a Nicolet $5 S X C$ FTIR spectrometer with a DTGS detector at a resolution of $4 \mathrm{~cm}^{-1}$. Gas phase $C O$ bands were eliminated by subtracting the absorbance of gas phase co with $\mathrm{SiO}_{2}$ disk in the cell from the spectra of adsorbed species on the Rh/SiOz catalyst.

\section{Results}

\section{Addition of Ethylene to Syngas}

Addition of ethylene to syngas over $\mathrm{Rh} / \mathrm{SiO}_{2}$ was studied using a feed consisting of $5 \%$ ethylene in the mixture of syngas with $\mathrm{CO} / \mathrm{H}_{2}=1$ in $393-573 \circ \mathrm{K}$ and $1.01 \mathrm{MN} / \mathrm{m}^{2}$. Table I shows the product distribution for the reaction. At temperatures below $453 \circ \mathrm{K}$, the major products of the reactions are propionaldehyde and ethane indicating that ethylene hydroformylation and hydrogenation are dominant. At temperatures above $513{ }^{\circ} \mathrm{K}$, methane and $\mathrm{C}_{2}$ + hydrocarbons were observed. Ethylene hydroformylation and hydrogenation appear to accompany with the $E-T$ reaction. A recent study by sze in our laboratory showed that the concentration of added ethylene did not affect the selectivity of ethylene 
hydroformylation; the rate of formation of ethane and propionaldehyde increased proportionally with the concentration of added ethylene [13].

\section{In Situ IR study}

Figure 1 shows IR spectra of CO adsorption, CO hydrogenation, and ethylene hydroformylation on $\mathrm{Rh} / \mathrm{SiO}_{2}$ at $513 \mathrm{\circ}^{\circ} \mathrm{K}$ and 1.01 $M N / m^{2}$. Two major bands were observed for CO adsorption and CO hydrogenation: Iinearly adsorbed co at 2043 m-1 and bridgebonded CO near $1890 \mathrm{~cm}^{-1}$. Methane was identified as the major product; acetaldehyde and $\mathrm{C}_{2}+$ hydrocarbons were observed as the minor products during the co hydrogenation under this condition.

When ethylene was added to $\mathrm{CO} / \mathrm{H}_{2}$ to initiate hydroformylation, both linear- and bridge co-bands shifted downward in wave number and decreased in the absorbance compared to both $\mathrm{CO}$ bands before ethylene addition. The downward shift in both 1 inear- and bridge-CO wave number has been attributed to the decrease in the dipole-dipole coupling between adsorbed CO as a result of dilution of adsorbed co by adsorbed ethylene species [18]. The decrease in the absorbance of both linear-and bridgeCo appears to be due to a decrease in CO partial pressure as a result of ethylene addition. A new set of bands was also observed during the hydroformylatior. IR bands near 1466 and 1416 $\mathrm{cm}^{-1}$ may be assigned to the bend vibration of hydrocarbons or a]kyl part of propionaldehyde [19]; bands around 2880-2980 $\mathrm{cm}^{-1}$ may be assigned to $\mathrm{C}-\mathrm{H}$ stretching vibrations of hydrocarbon 
species $[19,20]$. IR bands at $1722 \mathrm{~cm}^{-1}$ are assigned to adsorbed propionaldehyde on the catalyst. The assignment was confirmed by IR spectra of adsorption of propionaldehyde on the catalyst and $\mathrm{SiO}_{2}$ support. The band of interest at $1678 \mathrm{~cm}^{-1}$ may be assigned to a surface acyl group $\left(\mathrm{CH}_{3} \mathrm{CH}_{2}(\mathrm{CO})-\mathrm{Rh}\right)$. This assignment is in line with the observation of $1670 \mathrm{~cm}^{-1}$ which was identified as an a.cyl compound \{Rh6 $(\mathrm{CO})_{15}\left(\mathrm{CH}_{3} \mathrm{CH}_{2} \mathrm{CO}\left[\mathrm{NMe}_{4}\right]\right\}$, in a homogeneous hydroformylation study [21].

IR studies of ethylene hydroformylation was repeated on a fresh catalyst under $1.01 \mathrm{MN} / \mathrm{m}^{2}$ and $513 \mathrm{o}$. Following the reaction study, the reactant flow was stopped; the reactor pressure and temperature was decreased to $1.01 \times 10^{5} \mathrm{~N} / \mathrm{m}^{2}$ and $298^{\circ} \mathrm{K}$. Spectra taken subsequently showed that the spectra of adsorbed species remained almost the same as those under reaction conditions except that the acyl band showed an increase in the absorbance. The reactivity of all of the adsorbed species to hydrogen was examined by temperature programmed reaction with hydrogen. The study was carried out by introduction of a flow of $\mathrm{H}_{2}$ into the IR cell at $10 \mathrm{cc} / \mathrm{min}$. and the reactor was heated at $3.5 \mathrm{o} / \mathrm{min}$. Spectra taken is shown in the Figure 2. Absorbance of acyl band was rapidly decreased while the absorbance of propionaldehyde band was slowly attenuated as temperature increased. Gas chromatograph analysis of the gas phase product in the reactor effluent showed that propionaldehyde and $\mathrm{CH}_{4}$ are major products during temperature programmed reaction. The band 
near $1722 \mathrm{~cm}^{-1}$ which remained almost unchanged after more than 1 $\mathrm{hr}$. of reduction in $\mathrm{H}_{2}$ at $513 \circ \mathrm{K}$ may be attributed to the adsorbed propionaldehyde on $\mathrm{SiO}_{2}$.

A slight shift in the wave number of both linear and bridge co to lower wave numbers was observed as the temperature increased to $473 \circ \mathrm{K}$. Both types of adsorbed co were almost completely desorbed at $513{ }^{\circ} \mathrm{K}$ while substantial amount of adsorbed hydrocarbons remained on the surface.

Figure 3 shows the IR spectra of co adsorption, co hydrogenation, and ethylene hydroformylation on sulfided $\mathrm{Rh} / \mathrm{SiO}_{2}$. Comparing IR spectra in the Figure 3 with those in the Figure 1 showed that (i) adsorbed sulfur inhibited adsorption of co in the bridged form and shifted the wave number of linear $\mathrm{CO}$ to a higher wave number, (ii) a shoulder near $2020 \mathrm{~cm}^{-1}$ appeared on the CO adsorption and $\mathrm{CO}$ hydrogenation and became a dominant bend in the ethylene hydroformylation on the sulfided Rh catalyst; the absorbance of the bard appears to be independent of the co partial pressures, and (iii) acyl band was not observed on the sulfided catalyst. Analysis of gas phase products for the hydroformylation showed that propionaldehyde and ethane were major products and only trace of methane was observed. The results agree well with our previous study on the same $\mathrm{Rh} / \mathrm{SiO}$ catalyst showing that sulfur poisoned methanation, slightly inhibited the ethylene hydrogenation, but essentially had no effect on the rate of formation of propionaldehyde [22]. 


\section{Discussion}

Adsorption of $\mathrm{CO}$ on the $\mathrm{Rh} / \mathrm{SiO}_{2}$ and the sulfided $\mathrm{Rh} / \mathrm{SiO}_{2}$

Two forms of adsorbed $C O, l$ inear and bridge $c 0$, have been observed during the $C O$ adsorption and $\mathrm{CO}$ hydrogenation on $\mathrm{Rh} / \mathrm{SiO}_{2}$ at $513 \circ \mathrm{K}$ and $1.01 \mathrm{MN} / \mathrm{m}^{2}$. Similar observations have been reported on the co hydrogenation studies on La-Rh/SiO2 [23] and $\mathrm{Rh}-\mathrm{Ir}-\mathrm{Mn}-\mathrm{Li} / \mathrm{SiO}_{2}$ [24]. In contrast, three forms of adsorbed CO (Iinear, bridge, and twin) have been identified on the supported Rh catalyst. Twin carbonyl was generally considered to bond to isolated Rh sites [25]. Solymosi and Pasztor [26] has reported that $\mathrm{H}_{2}$ prevent the formation of isolated Rh sites at temperature above $373 \circ \mathrm{K}$. In addition, twin carbonyl is more reactive toward hydrogen than linear CO and bridge CO [27]. It appears that the formation of stable dicarbonyl species is not favorable under co hydrogenation and hydroformylation conditions.

Sulfidation of the catalyst led to modification of adsorbed CO: an upward shift of linear-CO wave number, a significant decrease in bricge-CO absorbance and downward shift of bridge co wave number, and the appearance of a new band at $2020 \mathrm{~cm}^{-1}$. The shift of the co wave number has often been used to characterize the electronic state of metal catalysts. The adsorbed co gave a higher wave number on the metal ion (or metal with partial positive charge) than that on the zero-valent metal surface [9]. The linear bands at $2043 \mathrm{~cm}^{-1}$ for $\mathrm{Rh} / \mathrm{SiO}_{2}$ and at $2061 \mathrm{~cm}^{-1}$ for sulfided $\mathrm{Rh} / \mathrm{SiO}_{2}$ observed in this study are in the range of 2073- 
$2040 \mathrm{~cm}^{-1}$ which has been assigned to linear co on the zero-valent Rh surface $[25,26]$. The small upward shift $\left(18 \mathrm{~cm}^{-1}\right)$ of linear co band appears to be insufficient to justify the possible formation of $R^{+}$(or partial positive $R h$ ) on the surface of the sulfided Rh catalysts.

The decreased bridge-CO absorbance on the sulfided catalyst suggests that adsorbed sulfur disrupts ensemble site for bridge Co and Co hydrogenation without blocking sites for 1 inear CO and hydroformylation. It clearly indicates that the bridge co is not responsible for the hydroformylation; hydroformylation is less structure sensitive than hydrocarbon synthesis of the co hydrogenation.

The band observed at $2020 \mathrm{~cm}^{-1}$ on sulfided $\mathrm{kh} / \mathrm{SiO}_{2}$ appear to be different from that at $2016 \mathrm{~cm}^{-1}$ for hydroformylation on $\mathrm{Rh} / \mathrm{SiO}_{2}$. The wave number and absorbance of the former appears to be relatively insensitive to the change in co partial pressure from $.26 \mathrm{MN} / \mathrm{m}$ to $1 \mathrm{MN} / \mathrm{m}$ as hydrogen and ethylene were added to the reactant stream. This band at $2020 \mathrm{~cm}^{-1}$ could be assigned to a surface carbonyls species. The band resembles those of $\mathrm{Rh}(\mathrm{CO})_{4}$ which was reported to give bands at 2020 and $2010 \mathrm{~cm}^{-1}$ [28]; it is also in line with the observed IR band of co vibration of the proposed $\mathrm{C}_{2} \mathrm{H}_{5} \mathrm{Rh}(\mathrm{CO})$ which was considered to be a reaction intermediate in the homogeneous hydroformylation [29]. It is known that sulfur overlayer tends to promote the formation of metal carbonyl form metal [30]. Our recent study has also 
shown that $\mathrm{H}_{2} \mathrm{~S}$ enhances the formation of $\mathrm{Ni}(\mathrm{CO})$ from $\mathrm{Ni} / \mathrm{SiO}$ catalyst during co adsorption, co hydrogenation, and hydroformylation.

Comparison of in situ IR results with those of our current and previous reaction studies $[13,22]$ revealed that in spite of the ahsence or presence of carbonyl band at $2020 \mathrm{~cm}^{-1}$ and the difference in the wave number of linear-co band on the Rh catalysts, both Rh/sicz and sulfided Rh/SiOz exhibited essentially the same activity for the ethylene hydroformylation. It remains unclear about the role of surface carbonyl species in the hydroformylation on the supported Rh. Our results are not able to provide definitely evidence to clarify the current controversy on the state of active sites for the co insertion step in both hydroformylation and co hydrogenation on supported retal catalysts $[31-34]$.

Mechanistic Relationships Between Homogeneou and Hetreogeneous Hydroformylation

Mechanistic studies of homogeneous hydroformylation have revealed that the reaction proceeds via (i) activation of catalyst by transformation of the parent carbonyl into a hydridocarbonyl, (ii) a formal insertion of an olefin into a metal-H bond of the hydrjdocarbonyl to from an alkylmetal complex - (iii) a formal migratory insertion of a co into an alkyl-metal bond of alkylmetal complex to form an acyl species, and (iv) hydrogenolysis of the acyl species to give an aldehyde with the 
regeneration of the catalysts $[1-7,35,36]$.

The key step in the homogeneous hydroformylation which can be used to develop mechanistic relationship between homogeneous and heterogeneous hydroformglation appears to be the migratory insertion of co into an alkylmetal bond to form an acyl-metal complex Take rhodium complex catalyst as an example.

$\mathrm{CH}_{3} \mathrm{CH}$ ? $\mathrm{Rh}(\mathrm{CO})_{3}+\mathrm{CO}--->\mathrm{CH}_{3} \mathrm{CH}_{2} \mathrm{Rh}(\mathrm{CO})_{4}--\rightarrow \mathrm{CH}_{3} \mathrm{CH}_{2}(\mathrm{CO}) \mathrm{Rh}(\mathrm{CO})_{3}$

A number of in-situ infrared spectroscopic studies on the homogeneous hydroformylation have shown that the migratory co insertion takes place in Rh carbonyl system [29,37]. King et al. [29] found that $\mathrm{C}_{2} \mathrm{H}_{5} \mathrm{Rh}(\mathrm{CO})_{4}$ is the most abundant reaction intermediate in ethene hydroformylation over alkylrhodium tetracarbonyl derivative catalysts. Although the acyl complex has not been observed during hydroformylation by in situ IR, the acylcomplex intermediates in the reaction have been isolated and characterized by IR [21]. The observation of acyl band indicates that the acyl intermediate, $\mathrm{CH}_{3} \mathrm{CH}_{2}(\mathrm{CO})-\mathrm{Rh}$, is present on the surface of $\mathrm{Rh} / \mathrm{SiO}_{2}$ durino the heterogeneous hydroformylation. The results suggest the migratory co insertion may take place on the supported $R h$ catalysts leading to the formation of acyl intermediate. Temperature programmed reaction study (shown in Figure 2) revealed that the acyl species can be hydrogenated to form propionaldehyde. It is important to point out that our IR study was carried out under steady state condition which provides the spectra of all the adsorbed species including reaction inter- 
mediates and spectator species ( surface species which do not involve in the reaction). An isotopic transient FTIR study incorporated with mass spectroscopy is under way to distinguish reaction intermediates from spectator species.

It is important to note that the incapability of sulfur compounds to poison hydroformylation over supported metal is, in some respects, similar to that observed with hydroformylation over metal carbonyl. Freund and Marko [16] have shown that metal carbonyls remain active in catalyzing hydroformylation in the presence of sulfur species which slowly deactivate the reaction. Sulfided Rh catalysts appears to exhibit more catalytic property similarities to Rh carbonyls and complexes than Rh metal; both sulfided $R h$ and $R h$ complexes are inactive for the hydrocarbon synthesis of the co hydrogenation while Rh metal is active for co hydrogenation; acyl species which was not observed in in situ IR studies on both sulfided $R h$ and $R h$ carbonyl systems [ 29 ]. The acyl species is probably not the abundant intermediate in the hydroformylation over both sulfided $\mathrm{Rh}$ and $\mathrm{Rh}$ carbonyl.

\section{Conclusions}

Adsorbed acyl species wos observed on $\mathrm{Rh} / \mathrm{SiO}_{2}$ catalyst during ethylene hydroformylation by in situ IR technique. The results suggest that the insertion of $\mathrm{CO}$ into adsorbed ethyl specie takes place on the Rh/SiO2. Addition of $\mathrm{H}_{2} \mathrm{~S}$ on the $\mathrm{Rh} / \mathrm{SiO}_{2}$ blocked the bridge-CO sites and inhibited the formation of hydrocarbons from Co hydrogenation. In contrast. H2S addition slightly affected 
the vibrational frequency of linear $C O$, and essentially had no effect on the hydroformylation activity. Adsorbed sulfur also promoted the formation of carbonyl species which roles in catalysis remains unclear. Hydroformylation on sulfided $\mathrm{Rh} / \mathrm{SiOz}$ appears to resemble homogeneous hydroformylation to a greater extent compared io the hydroformylation on $\mathrm{Rh} / \mathrm{SiO}_{2}$. 


\section{References}

1. I. Wender and P. Pino, Organic Srnthesis via Metal Carbonvis, wiley, New York, $197 i$.

2. G. Henrici-Olive and S. Olive, The Chemistry of the Catalrzed Hrdrogenation of Carbon Monoxide, Spring-Verlag, 1984.

3. C. Masters, Homogeneous Transition-Metal Catalysis - a gentle art, Chapman and Hall, New York and London, 1981.

4. O. Roelen, German Pat. $849548,1938$.

5. I. Wender, $H$. H. Sternberg and $M$. Orchin, in P. H. Emmett (ed.), Catalrsis. Vol. 5, Reinhold, New York, 1957, p. 73.

6. I. Wender, H. W. Sternherg and M. Orchin, J.Am. Chem. Soc., I3 $(1953) 3041$.

T. R. A. Sheldon, Chemicals from Srnthesis Gas, D. Reidel Pub. Co., Bostan, 1983.

8. S. C. Chuang, J. G. Goodwin, Jr. and I. Wender, J. Catal., 95 (1985) 435 .

9. Y. Konishi, M. Ichikawa and W. M. H. Sachtler, J. Phys. Chem., $91(1987) 6286$.

10. D. S. Jordan and A. T. Bell, J. Phys. Chem.990 (1986) 4797

11. M. Pijolat and V. Perrichon, Appl. Catal., 13 (1985) 321.

12. M. Ichikawa, J. Catal. 56 (1979) 127.

13. C. Sze, M.S. Thesis, Univ. of Akron, 1989.

14. D. G. Castner, R. L. Blackadar and G. A. Somorjai, J. Catal.. 66 (1980) 257 .

15. W. M. Sachtler and M. J. Ichikawa, J. Phys. Chem., 90 (1986) 4752 .

16. M. Freund and L. Marko, Bernnstoff-Chemie, 46 (1965) 100 ,

17. C. H. Bartholomew, P. K. Aqrawal and J. R. Katzer, Adv. Catal. $31(1982) 135$.

18. F. Stoop, F. J. C. Toolenaar and V. Ponec, J. Catal., 70 $(1982) 50$.

19. M. L. Hair, Infrared Spectroscopy in Surface Chemistry, Dekker, New Fork, 1967. 
20. J. G. Ekerdt and A. I. Bell, J.Catal.. 58 (1979) 170.

21. P. Chini, S. Martinengo and G. Garlaschelli, J.Chem. Soc.. Chem. Commun., (1972) 709 .

22. S. C. Chuang and C. Sze, in J. W. Ward led.l, Catalrsis, Vol. 38, Elsevier, Neh York, 1987, P. 125.

23. R. P. Underwood and A. T. Bell, J. Catal.. $111(1988) 325$

24. T. Nakajo, H. Arakara, K. Sano and $S$. Matsuhira, Chem. Lett., (1987) 593 .

25. J. T. Yates, Jr., M. T. Duncan and R. W. Vaughan, J. Chem. Phrs.. $71(1979) 3908$.

26. F. Solrmosi and M. Pasztor, J. Phys. Chem., 90 (1986) 5312 .

27. S. Zhong, J Catal., $100(1986) 270$.

28. L. A. Halan and G. A. Ozin, J.Am. Chem. Soc.. 96 (1974) 6324 .

29. R. B. King, A. D. King and M. Z. Iqbal, J. Am. Chem. Soc., $101(1979) 17$.

30. F. Calderazzo, R. Ercoli and G. Natta, in I. Wender and P. Pino (eds.), Organic Srntheses via Metal Carbonrls. Vol. 1 , Wiley, New York, 1968, P. 1 .

31. F. G. A. van den Berg, J. H. E. Glezer and W. M. H. Sachtler, J. Catal. $93(1985) 340$.

32. G. van der Lee and V. Ponec, J. Catal., 99 (1S86) 511.

33. H. J. Gysling, J. R. Monnier and G. Appai, J. Catal.. 103 (1987) 407 .

34. H. Orita, S. Naito and K. Tamaru, Chem. Lett., (1983) 1161.

35. R. Whyman, J. Ore. Chem., 81 (1974) 97.

36. F. Calderazzo, Angew. Chem. 89 (1977) 305.

37. G. Yaqupsky, C. K. Brown and G. J.Wilkinson, J. Chem. Soc. (A), (1970) 1932 . 
Table 1. Product selectivity of CO/H2/C2 Ht Reaction over $\mathrm{Rh} / \mathrm{SiO}_{2}$

$\mathrm{I}(\circ \mathrm{K})$

393

453

513

573

Urerall Rate

of $\mathrm{C}_{2} \mathrm{H}+$
$(g m o l / k g-h r)$
$6.1 E-2$
4. $9 \mathrm{E}-1$
5. 1 EO
3. $3 \mathrm{E} 1$

Product

Selectivity

(mol \%)

$\begin{array}{lrrrr}\mathrm{CH}_{4} & 0.0 & 0.0 & 4.3 & 7.8 \\ \mathrm{C}_{2} \mathrm{OxYg} & 0.0 & 0.0 & 2.2 & 2.4 \\ \mathrm{C}_{3}+\mathrm{HC} & 0.0 & 0.0 & 0.3 & 0.5 \\ \mathrm{C}_{2} \mathrm{H}_{6} & 35.2 & 46.3 & 60.9 & 76.4 \\ \mathrm{C}_{2} \mathrm{H}_{5} \mathrm{CHO} & 64.8 & 52.8 & 30.7 & 8.0 \\ \mathrm{C}_{3} \mathrm{H}_{7} \mathrm{OH} & 0.0 & 0.9 & 2.0 & 4.9\end{array}$

Pressure $=1.01 \mathrm{MN} / \mathrm{m}^{2}$.

$5 \mathrm{~mol} \% \mathrm{C}_{2} \mathrm{H}_{t}$ in $\mathrm{CO} / \mathrm{H}_{2}=1$. 


\section{LIST OF FIGURES $\cdot$}

Fizure 1. Infrared spectra of $c 0$ adsorption, co hydrogenation. and ethylene hydroformylation on $\mathrm{Rh} / \mathrm{SiO}_{2}$.

Figure 2. Temperature programmed reaction of adsorbed species (from ethylene hydroformylation) with hydrogen.

Figure 3. Infrared spectra of CO adsorption, CO hydrogenation. and ethylene hydrotormylation on sulfided $\mathrm{kh} / \mathrm{SiO}_{2}$. 


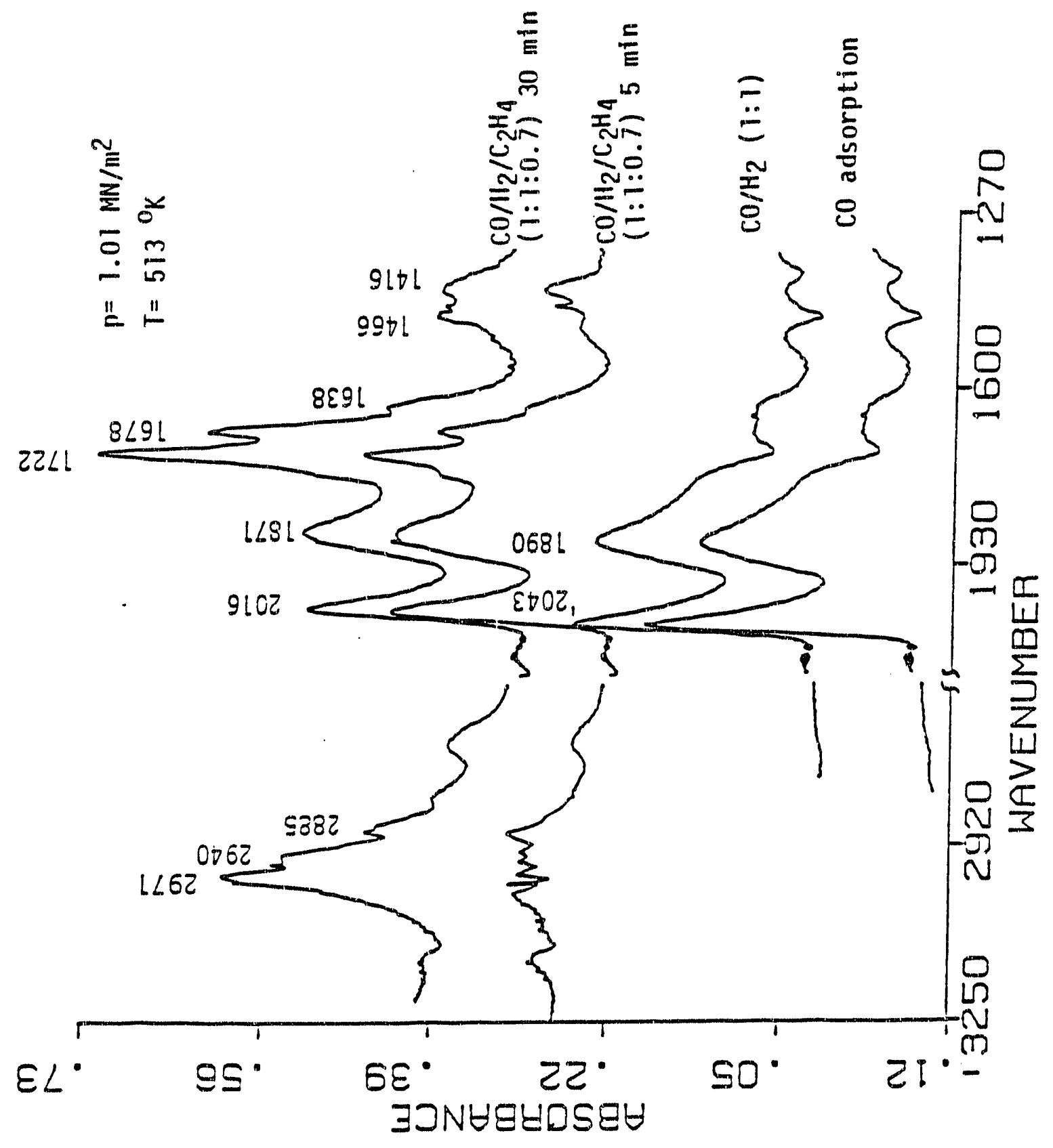













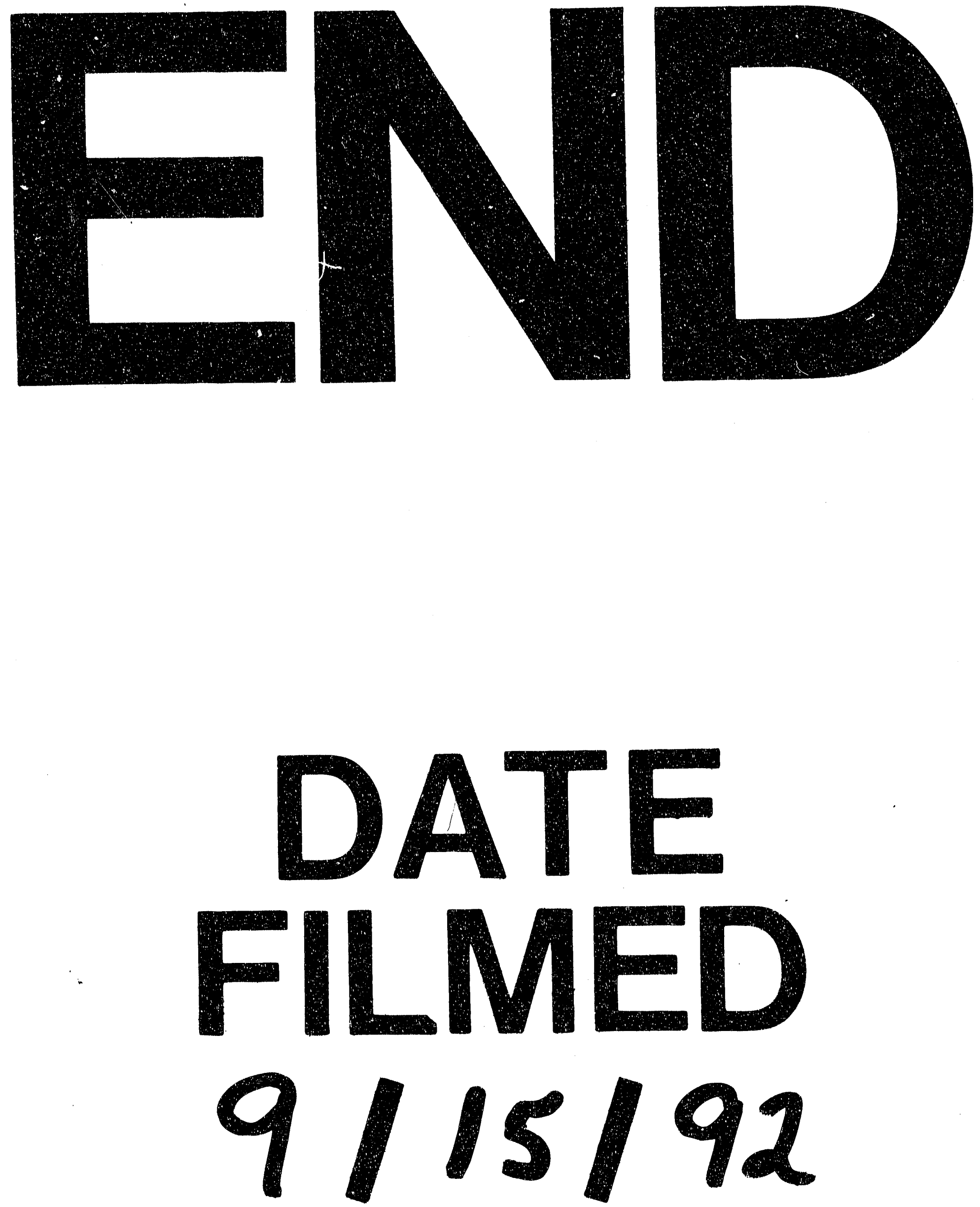
